\title{
Analysis On The Path And Difficulties Of Chemical Energy Marketization Reform
}

\author{
Dawei Wang ${ }^{1, a}$ \\ ${ }^{1}$ State Grid Liaoning Electric Power Co., LTD., Shenyang, Liaoning, China
}

\begin{abstract}
Chemical energy market-oriented reform is a series of important meeting requirements of the central government, which has a very arduous reform task in the context of the information age. In view of this phenomenon, analysis on the path and difficulties of chemical energy marketization reform. The market-oriented reform of chemical energy is the requirement of a series of important meetings of the central government, which has a very arduous reform task in the context of the information age. In view of this phenomenon, the path and difficulties of chemical energy market-oriented reform are analyzed. Build a complex of multiple system subtypes, integrate the price, output, benefit and other indicators of chemical materials to reach a balance point, and meet the different needs of market-oriented reform of different chemical energy enterprises; coordinate the overall reform of the whole industrial chain, including the toplevel design of the whole industrial chain reform, the combination of state-owned enterprise reform and chemical industry reform, and the reform of government approval In addition, we should take a comprehensive view of energy and environment, and vigorously develop renewable energy and clean energy. Through the analysis of the difficulties in the market-oriented reform of chemical energy, it is concluded that: at present, the administrative measures for the market-oriented reform of chemical energy in China are temporary but not permanent, most energy enterprises think that the attraction of the proposed policies is low and can not promote the market-oriented reform of chemical energy enterprises; the energy system can not be typified, and it is difficult to classify it as planned economy or market economy based on the atypical characteristics of chemical energy market Market economy increases the difficulty of chemical energy market-oriented reform.
\end{abstract}

\section{Introduction}

The chemical energy marketization reform is a key content of the Third Plenary Session of the 18th CPC Central Committee, and the dominant position of the market in chemical energy allocation issues is clarified ${ }^{[1]}$. The main message of the meeting is that our country must speed up the pace of chemical energy market reform, and further promote the subtype of the dual chemical energy system into the market subtype. As soon as this signal was sent out, heated discussions began in the domestic chemical energy industry ${ }^{[2]}$. All units in the chemical energy industry, with marketoriented reform as the theme, have made phased achievements through path practice and achieved remarkable results. The level of market-oriented construction, management and service of chemical energy enterprises has been steadily improved, which strongly supports the overall situation of market-oriented reform and development of the chemical energy industry. The path of market-oriented chemical energy reform represents a new productivity and development direction. We must actively promote the market-oriented development mode of renewable chemical energy and non- renewable chemical energy, the construction of chemical energy market system and the pilot operation of market-oriented transformation of comprehensive chemical energy. In the analysis of the path and difficulty of chemical energy marketization reform in China, the research on this aspect mainly focuses on the continuous improvement of building capacity. Based on Cong Xinxing's thoughts and suggestions on speeding up the market-oriented reform of China's refined oil products, this paper puts forward the path analysis of the market-oriented reform of chemical energy resources according to the requirements of the times, and analyzes the difficult problems in the process of the marketoriented reform of chemical energy resources, so as to push forward the process of the market-oriented reform of China's chemical energy resources and promote the rapid growth of China's market economy fundamentally.

\section{Path analysis of chemical energy market reform}

Before the path analysis of chemical energy market reform, it is necessary to make clear that chemical energy has the nature of commodity. Since chemical energy is commodity, resources should be allocated by

âE-mail: wangdw@ln.sgcc.com.cn 
market. Based on this, this paper puts forward three paths in the chemical energy market reform, which constitute a complete framework of chemical energy market reform path ${ }^{[3]}$. The chemical energy market reform path framework, as shown in Figure 1.

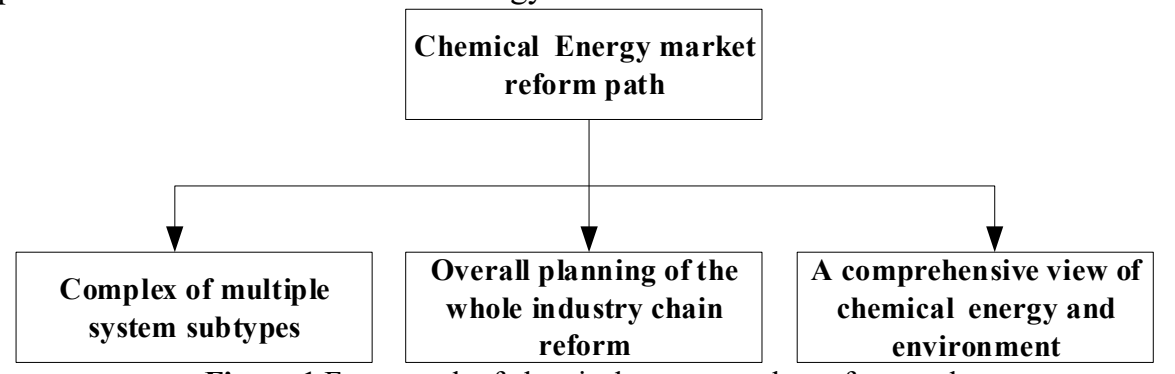

Figure 1 Framework of chemical energy market reform path

Combined with Figure 1, the following three points of chemical energy market reform path for specific research.

\subsection{Multiple-subtype complexes}

In the chemical energy market reform, because most of the chemical energy enterprises are based on the dual system, and the multiple system subtype is based on the market system and the dual system subtype of coexistence ${ }^{[4]}$. The chemical energy marketization reform not only puts forward specific requirements for price, output and efficiency, but also fully considers the demands for environmental, chemical energy saving and emission reduction indicators. Through the establishment of a complex of multiple system subtypes, these indicators will be integrated to achieve a balance point to meet the different needs of market-oriented reform of different chemical energy enterprises. By designing the Gantt Circle of the annual implementation time and schedule of the chemical energy market reform project and combining with the marketing strategy of multichemical energy products, we can jointly create a complex of multi-system subtypes. The chemical energy market reform is different from other industries, we must consider the comprehensive chemical energy sustainable business model, can be called exogenous plan, dual-track chemical energy market reform.

\subsection{Reform of the whole industrial chain with overall planning}

The overall overall reform of the whole industry chain mainly includes: top-down design reform of the whole industry chain, combination of the reform of state-owned enterprises with the reform of industries, and reform of the examination and approval and supervision system of the government ${ }^{[5]}$. Top design of the entire industrial chain reform must be clear about the goal of the chemical energy market reform, the incomplete market chain into a complete market industrial chain. Top design is mainly aimed at chemical energy executives in the design, through the top to drive the bottom of the system reform, to create a complete market industry chain. The combination of the reform of state-owned enterprises and the reform of industries is the key content of the reform of the whole industrial chain with overall planning. chemical energy enterprises may formulate reform measures suitable for their own enterprises in combination with the reform mode of state-owned enterprises. Absorb the successful advanced experience of the market-oriented reform of state-owned enterprises, find profit points in comparison with the market-oriented reform mode of their own chemical energy enterprises, timely discover correctable aspects, and make overall plans for innovating the service mode of chemical energy enterprises. The reform of the examination and approval and supervision system of the government requires that the overall reform of the whole industry chain must rely on the supervision function of the government, combine with the government, and return part of the examination and approval authority to the chemical energy enterprises. Overall planning of the entire industrial chain reform system should be in line with the reality, with the goal of unity, in order to bloom a stronger force. In addition to the government's affirmation and support, but also put forward a "moderate competition to build a new mechanism" statement. Improve the practice of market-oriented chemical energy reform. Chemical energy enterprises may put forward various promotion policies in combination with government cultural subsidies, establish a good market reputation, create a relatively good social image, comprehensively promote the market-oriented reform of chemical energy enterprises, and promote the transformation of chemical energy enterprises into comprehensive chemical energy service providers.

\subsection{Comprehensive view of chemical energy and environment}

In the process of chemical energy market reform, chemical energy and environment issues should not be ignored, and great efforts must be made to develop renewable chemical energy and clean chemical energy ${ }^{[6]}$. The chemical energy market reform should be carried out on the basis of ecological environment protection, instead of blindly restricting chemical energy development for environmental protection. The chemical energy marketization reform needs a long-term process, which is not accomplished overnight, and so is the environmental protection. The degree of chemical energy utilization reflects the degree of social development. The level of chemical energy utilization is closely related to environmental protection. Clean 
chemical energy has little impact on the environment. It is necessary to strengthen the application of clean chemical energy, promote the market-oriented chemical energy reform, while minimizing the damage to the environment.

\section{Analysis of Difficulties Marketization of Chemical Energy}

in

By combing the problems existing in the chemical energy marketization reform, this paper analyzes the difficulties in the chemical energy marketization reform. This paper analyzes this problem from two angles: one is from the angle of administration, the other is from the angle of system, it is not sure whether the plan or the market is the chemical energy system. These two points have produced the restriction to the chemical energy marketization reform, it is necessary to carry on the key analysis to it.

\subsection{Temporary Solutions and Permanent Solutions}

Although many preferential policies for chemical energy market reform have been issued by local governments in the joint chemical energy market, they have not been implemented in practice. Administrative measures are only the external driving force for chemical energy market reform, but the most difficult point of chemical energy market reform is the lack of internal driving force [7]. In the chemical energy market reform, the most common temporary and permanent difficulties include: the contradiction between coal and electricity and the dispute over chemical energy price, which can not be effectively solved by administrative measures, and all need to start from the internal chemical energy enterprises. The work of various departments of chemical energy enterprises shall be separated from and intermingled with each other, the industry investigation and research shall be carried out on a regular basis, the status quo and development trend of market-oriented reform of chemical energy enterprises in different regions shall be understood, and the market-oriented reform strategies of chemical energy enterprises shall be adjusted according to real data, so as to provide sufficient space for the sustainable development of chemical energy enterprises.

In the current chemical energy market reform, the contradiction between supply and demand and price is the biggest obstacle to the market-oriented reform, which has been taken the corresponding administrative measures, but have not achieved good results. According to the market survey feedback data, most chemical energy enterprises consider that the proposed policies are less attractive and cannot promote the market-oriented reform of chemical energy enterprises, and the policies have not been really implemented in the implementation process, and there is a phenomenon that temporary solutions are not permanent solutions. The phenomenon of default in the market-oriented reform of chemical energy enterprises is also the main manifestation of inadequate implementation of the policy. We should respond to the call of national politics, let chemical energy enterprises feel the benefits of market-oriented reform on the future development of chemical energy enterprises, encourage more chemical energy enterprises to participate in the market-oriented reform, enhance the impact of policies on the market-oriented reform of chemical energy enterprises, and enhance the internal power of the market-oriented reform of chemical energy enterprises. In the process of market-oriented reform of chemical energy enterprises, regular surveys shall be conducted to get a real-time grasp of the understanding of policies of chemical energy enterprises. With regard to the policy information fed back by chemical energy enterprises, the functional departments of the government shall carry out market research, and promote the market-oriented reform of chemical energy through targeted treatment of specific problems that are not fully implemented.

\subsection{Chemical Energy systems cannot be typified}

The reform of chemical energy market calls for the basic characterization of the current chemical energy system, and the difficulty lies in the inability to model the chemical energy system. Given the atypical nature of chemical energy markets, it is difficult to categorize them as planned or market economies ${ }^{[8]}$. For example, in our country, the chemical energy system occupies a large proportion of electric power, and its enterprise structure usually belongs to many kinds of ownership systems. The problem that the chemical energy system can not be typified greatly limits the chemical energy market reform. Chemical energy enterprises should not only meet the needs of the government, but also fully consider the market trend, which will undoubtedly increase the difficulty of the chemical energy market reform.

The chemical energy market reform requires the chemical energy enterprises to trade according to the market research, but because the chemical energy system has not completed the market reform, the overall chemical energy operating mechanism can not be really reformed. As long as the chemical energy system can not be typified, there will be no way to analyze it from the viewpoint of planned economy or market economy, which will lead to many difficulties in the chemical energy market reform. However, the chemical energy market reform is imperative, and the prospects are very bright, although there are some difficulties, but there is reason to believe that the goal of chemical energy market reform will be achieved.

\section{Conclusions}

Through the analysis of the path and difficulty of the chemical energy marketization reform, we can get some achievements. While seeing the achievements, we should also clearly realize that there are still some problems in the analysis of the path and difficulties of the current chemical energy market reform, such as insufficient understanding, relatively lagging behind the application 
of new technologies, and incomplete system. Chemical energy enterprises need to strengthen the awareness of overall situation, crisis and responsibility, and promote the chemical energy market reform. The informationization has brought the rare opportunity for the chemical energy marketization reform. As an important industry in China's economic system, chemical energy enterprises must seize the historical opportunity of informatization development and promote the development of chemical energy marketization reform. Therefore, there is reason to strengthen the research on chemical energy market reform and promote chemical energy market reform. In the future development of chemical energy enterprises, we must look at the general trend, a profound understanding of the information age opportunities and challenges.

\section{References}

1. Qi Xiao. Difficulties and breakthroughs in energy price reform[J]. Chinese Industry \& Economy, 2020, 1(4):107-109.

2. LV Jianzhong. Difficulties and reflections of energy reform in Mexico[J]. World Petroleum Industry, 2019, 26(4):1-4.

3. Cong Xinxing. Thoughts and suggestions on accelerating the market-oriented reform of China's refined oil products[J]. International Petroleum Economics, 2018, 26(12):18-22.

4. Yuan Shun. Unswervingly push forward the marketoriented reform of northeast electric power to realize energy efficient utilization and green development[J]. China Electric Power, 2018, 1(11):88-89.

5. Yang Qiang. Reform and opening up promote the development of Yunnan power market reform[J]. China Power Enterprise Management, 2018, 1(34):45-49.

6. Huang Hui, Zhou Hailang, Yang Huabing, et al. Foreign power market reform and development and Its Enlightenment to China[J]. China Market, 2019, $1(5): 63-65$

7. Xu Qiushi, Zhou Xiaobing, Yang Dongjun, et al. Study on Goal and Mentality of Power Grid Planning after Power Market Reform[J]. Hubei Electric Power, 2018, 42(6):27-31+37.

8. Wang Peng, Cao Yujie. Review and Prospect of power market reform in $2018[\mathrm{~J}]$. China Power Enterprise Management, 2019, 1(13):54-57. 